\title{
New and old, ethical and technical dilemmas in experimental medicine
}

\author{
Markovic $\mathrm{L}^{1 *}$ and Pantic $\mathbf{I}^{2}$ \\ ${ }^{1}$ Institute of Pathological Physiology, University of Belgrade, Faculty of Medicine, Belgrade, Serbia \\ ${ }^{2}$ Institute of Physiology, University of Belgrade, Faculty of Medicine, Belgrade, Serbia
}

\begin{abstract}
Today, medicine has a central place between natural and anthropological sciences. The basic method of most fundamental medical sciences, is an experiment. However, during some experiments, there are many technical and ethical dilemmas regarding the motive and goals of the research, as well as the way the research is being conducted. Moral rules and ideals provide the basis of ethical conduct in medical research, prohibiting unacceptable behavior and inspire us, researchers, to act in a manner that ensures humanity in our work. Ethical principles of experimentation should rely on the moral culture of a physician, as a key part of his professionalism.
\end{abstract}

\section{Introduction}

The root of the word "medicine" is derived from Indo-European "med" which means "mean" or "measure". Today, medicine has a central place between natural and anthropological sciences (social sciences, humanities) [1]. In medicine, especially in its branch pathological physiology, or pathophysiology, many achievements of fundamental and applied science are synthesized into one academic discipline. The basic method of pathological physiology, based on empiricism (the doctrine that knowledge derives from experience), is an experiment [2]. In an experiment, researchers observe certain natural phenomenon, in controlled, and sometimes, deliberately altered conditions. However, during some experiments, there are many technical and ethical dilemmas regarding the motive and goals of the research, as well as the way the research is being conducted. Some professionals state that a major question at the intersection of medicine and philosophy is "How ought we to practice medical research?", and to answer that question, physicians, scientists, lawyers, policy makers, and philosophers vet difficult yet alluring issues such as the nature of research, the requirements of informed consent, the role of money in research etc [3]. Moral rules and ideals provide the basis of ethical conduct in medical research, prohibiting unacceptable behavior and inspire us, researchers, to act in a manner that ensures humanity in our work. Moral ideals that are followed in basic medical sciences, such as pathophysiology, are the same as those ideals present in good medical practice (clinical medicine).

Morality is a central code of human relations. Most religions, as well as ethics as a science, put morality as the single, most important aspect of human behavior. Most authors agree with the definition that ethics is a unique branch of philosophy that deals with values related with human conduct, with respect to the rightness and wrongness of certain actions and to the goodness and badness of the motives and ends of such actions [4].

Today, different forms of knowledge that are given to us by modern science cannot be covered by a simple philosophical principle. Although traditional ethical analysis has a great value to humanity, it is sometimes difficult to give an adequate moral assessment of modern technologies of today, without observing their sociological, political and economical dimension. Scientists, sometimes, do not know how the knowledge that they discover, will be used in the future. Some authors suggest that a new science, "metascience", a science where physical, the psychological and the spiritual realms are integrated into a unity, might be needed in order to establish the connection between the conventional philosophy, ethics, and social and humanistic aspects of scientific practice (Meta-Science, see references). This is especially true, knowing that science is today rapidly changing, not only in research techniques and organizational structure but also in its relations with the society [5].

Some authors believe that there is a wide gulf that separates secular bioethics from Christian bioethics, and that Christian bioethics, unlike secular bioethics, understand that morality is about coming into a relationship with God [6]. This is especially true in modern times, when many intellectuals try to define moral and ethical values without the recognition of existence of God. As some scholars say, "The project of articulating a coherent, canonical, content-full, secular morality-cumbioethics fails, because it does not acknowledge sin, which is to say, it does not acknowledge the centrality of holiness, which is essential to a non-distorted understanding of human existence and of morality" [7]. Some important observations about God, science and philosophy were made by famous Christian philosopher, George Berkeley. "From my own being, and from the dependency I find in myself and my ideas, I do, by an act of reason, necessarily infer the existence of a God, and of all created things in the mind of God." [8]; "All the choir of heaven and furniture of earth - in a word, all those bodies which compose the frame of the world - have not any subsistence without a mind." [9]. Christian

Correspondence to: Ljiljana Markovic, PhD, Institute of Pathological Physiology, University School of Medicine, Belgrade, Serbia, Doktora Subotica 1/II, Belgrade, Serbia, E-mail: Ljiljana.markovic@med.bg.ac.rs

Key words: medicine, experiment, research, ethics

Received: November 28, 2017; Accepted: December 15, 2017; Published: December 19, 2017 
philosophy with its bioethics makes a unique and irreplaceable contribution by disclosing that one will see truly only insofar as one orients rightly in worship to the source of all being, God [10].

\section{Experiments in medical sciences}

Each diagnostic and therapeutic procedure is in a way, broadly speaking, an experiment on a human being. Many therapeutic measures and medications are applied to animal models before their use in humans. The main advantage of an animal research model is the ability to test a specific morphological, biochemical, immunological or metabolic disorder, that under present conditions cannot be studied in humans. However, animal models are not simple copies of human diseases.

Considering moral aspects of new medical technologies, it should be noted that many "new" techniques that modern medicine applies, were developed and used at some point in the past, even centuries ago. For example, the first experimental studies on animal artificial fertilization were performed by an Italian priest and physiologist Lazzaro Spallanzani (1729-1799) [11]. Every medical researcher should remember that most new medical technologies, in their essence do not pose a moral problem, however, the problem exists when a researcher or a doctor does not conform to basic moral principles when applying/ using that technology.

\section{Laws as ethical regulations}

Although modern laws define some principles in good scientific practice, some ethical values are either not present, or not completely covered by today's regulative. The medical experiments conducted by German doctors during The Second world war and prosecuted in the so-called "Doctors' Trial" resulted in the creation of the Nuremberg Code to control future experiments on humans.

Experiments on humans can be divided into two groups: experiments on patients where there is the possibility that research results will have a favorable impact on the disease, and experiments with scientific purposes only.

On 19th/20th August, 1947, the American military tribunal in the verdict on German physicians declared under the section "Permissible Medical Experiments" ten points, which are today known as the "Nuremberg Code", and have an immense importance in modern clinical research practice. Here, we state those principles (taken from United States Holocaust Memorial Museum, see references):

1. The voluntary consent of the human subject is absolutely essential.

2. The experiment should be such as to yield fruitful results for the good of society, unprocurable by other methods or means of study, and not random and unnecessary in nature.

3. The experiment should be so designed and based on the results of animal experimentation and a knowledge of the natural history of the disease or other problem under study that the anticipated results will justify the performance of the experiment.

4. The experiment should be so conducted as to avoid all unnecessary physical and mental suffering and injury.

5. No experiment should be conducted where there is an a priori reason to believe that death or disabling injury will occur; except, perhaps, in those experiments where the experimental physicians also serve as subjects.

6. The degree of risk to be taken should never exceed that determined by the humanitarian importance of the problem to be solved by the experiment.
7. Proper preparations should be made, and adequate facilities provided to protect the experimental subject against even remote possibilities of injury, disability, or death.

8. The experiment should be conducted only by scientifically qualified persons.

9. During the course of the experiment the human subject should be at liberty to bring the experiment to an end if he has reached the physical or mental state where continuation of the experiment seems to him to be impossible.

10. During the course of the experiment the scientist in charge must be prepared to terminate the experiment at any stage, if he has probably cause to believe, in the exercise of the good faith, superior skill and careful judgment required of him that a continuation of the experiment is likely to result in injury, disability, or death to the experimental subject. (United States Holocaust Memorial Museum, for details, see references)

Experiments on human subjects are as old as the history of medicine. There are written documents that such experiments were carried out on prisoners and slaves. In ancient times of Cleopatra, slaves were used to test some poisons. In Hippocrates' time, experiment on people was forbidden. However, in the period after Hippocrates, during the famous Alexandrian school, doctors performed vivisection of criminals and, thus, taught their students about the physiology and anatomy of man. In World War II, Nazi doctors in concentration camps monstrously performed vivisection and various other experiments on live human beings. Mengele, Epinger and other Nazi doctors ("The Boys from Brazil") remain a synonym for criminal, bestial relation towards humanity.

Professional ethics is the backbone of Medicine: Paracelsus (14931541), founder of pharmaceutical chemistry, knowing the thin line that separates a medicament and a poison, proclaimed the doctor's virtue and professional ethics ad the backbone of medicine [12].

In 1964 in Helsinki, Finland, The Declaration of Helsinki was developed by the World Medical Association as a set of ethical principles concerning experiments in medical practice.

In the preamble of the Helsinki Declaration it is stated: "Medical research is subject to ethical standards that promote respect for all human subjects and protect their health and rights." The Declaration of Helsinki and its six revisions also set the rule that no medical research on humans must be conducted, before adequate testing has been done on animals, while respecting all principles of ethics in veterinary medicine [13]. 3R Five years before Helsinki Declaration, "The principles of human experimental technique in the work with laboratory animals" was published. It was suggested that experiments on animals were to be replaced (Replace) with some other methods, to reduce the number of animals (Reduce) to a minimum and to improve (Refine) the conditions in experiments so that pain and stress of animals would be avoided [14]. However, some technical dilemmas with the implementation of the so-called $3 \mathrm{R}$ rule emerged.

"Replacement" is particularly a problem in toxicology. There are many examples of successful alternative methods. However, the application of these methods is usually limited to the laboratory where they were used, and require technology transfer. Unfortunately, many methods, when or if published in the scientific literature are not standardized, or nor reproducible.

Principle "reduction" is understandable, but there are difficulties in applying appropriate statistical methods in academic research. 
Sometimes it leads to lowering the number of animals to the point in which wrong research conclusions are made.

As for the moral aspects of animal protection, archbishop Suroski Anthony does not agree with Descartes' philosophy that animals are like machines which do not have a soul. The archbishop said that "We, human beings, doing it out of charity, help the animals and protect them from feeling pain, but we do not think about animals as beings that go to eternity like humans do" [15] Moral ideas for basic research give way to practical side of scientific research.

Many researchers think that animal experimentation will for the time being remain indispensable in biomedical research, although its role will shift in the direction of the confirmation of results obtained by animal-free methods [16-18].

All in all, growing public concern for the moral, social and economical role of science encourages us to think about what we, researchers, actually do. Ethical principles of experimentation should rely on the moral culture of a physician, as a key part of his professionalism.

\section{References}

1. Silujanova I V (2001) Orthodox Christianity and modern medicine Cetinje. SVETIGORA Izdavacka ustanova Mitropolije Crnogorsko-Primorske: 19-28

2. Vučevic D, Pesic B, Markovic Lj, Radosavljevic T, Zunic-Bozinovski S, et al. (2008) Place and role of pathophysiology in modern medicine Srp Arh Celok Lek 136: 25-32.

3. Tomas B (2008) Should We Be Alarmed by Medical Research? Journal of Medicine \& Philosophy. 33: 524-532.

4. Pozgar GD (2004) Legal aspects of health care administration. Boston: Jones \& Bartlett Publishers: 388.
5. Ziman J (2001) Getting scientists to think about what they are doing. Sci Eng Ethics 7: $165-176$

6. Engelhardt HT (2009) Moral Pluralism, the Crisis of Secular Bioethics, and the Divisive Character of Christian Bioethics: Taking the Culture Wars Seriously. Christian Bioethics 15: 234-253.

7. Engelhardt HT (2005) Sin and bioethics: why a liturgical anthropology is foundational. Christian Bioethics 11: 221-39

8. Berkeley G (2004) 1A Treatise Concerning the Principles Of Human Knowledge. Kessinger Publishing.

9. Winkler KP (1989) Berkeley: an interpretation. Oxford University Press: 287

10. Engelhardt HT (2004) Moral knowledge: some reflections on moral controversies incompatible moral epistemologies and the culture wars. Christian Bioethics 10: 79-103.

11. Gacto M (1999) The bicentennial of a forgotten giant: Lazzaro Spallanzani (17291799). Int Microbiol 2: 273-274.

12. Schefer H (1991) Medical ethos of Paracelsus. Schweiz Rundsch Med Prax 80: 1461-7

13. Villar J (1988) Recommendations of the Helsinki Declaration on clinical investigation and main guidelines in the care and use of animals. Med Clin (Barc)91: 702-703.

14. Autissier C (2008) Ethical review in biomedical research. Med Sci (Paris) 24: 437-442.

15. Pantelic Antonina (2007) Медицинска етика и Православље Православље НОВИНЕ СРПСКЕ ПАТРИЈАРШИЈЕ. http://pravoslavlje.spc.rs/broj/978/tekst/ medicinska-etika-i-pravoslavlje/ (accessed December 28, 2009)

16. Hendriksen CF (2006) Developments in the area of animal experiments in biomedical research. Ned Tijdschr Geneeskd 150: 2857-2862.

17. META-SCIENCE Towards an integrative universal Worldview for a better World and Humanity - Introduction. http://bpramana.tripod.com/, (accessed December 28, 2009).

18. United States Holocaust Memorial Museum. "The Holocaust." Holocaust Encyclopedia. http://www.ushmm.org/wlc/en/index.php?ModuleId=10005143 (accessed December 28, 2009).

Copyright: (C2017 Markovic L. This is an open-access article distributed under the terms of the Creative Commons Attribution License, which permits unrestricted use, distribution, and reproduction in any medium, provided the original author and source are credited. 